\title{
TRATAMENTOS PARA SUPERAÇÃO DA DORMÊNCIA EM SEMENTES DE CEVADA $^{1}$
}

\section{TREATMENTS FOR OVERCOMING DORMANCY OF BARLEY SEEDS}

\author{
Lilian Madruga de TUNES 2 \\ Pablo Gerzson BADINELLI ${ }^{3}$ \\ Franciéle OLIVO 2 \\ Antonio Carlos de Souza Albuquerque BARROS ${ }^{4}$
}

\begin{abstract}
RESUMO
O trabalho foi conduzido com o objetivo de estudar a eficiência de diferentes tratamentos para superar a dormência em sementes de cevada colhidas em diferentes épocas. Para tanto, utilizaram-se sementes da cultivar MN 721 e Scarlett, avaliadas separadamente. Os tratamentos utilizados foram os seguintes: pré-frio a temperatura de 5 a $10^{\circ} \mathrm{C}$; pré-secagem a temperatura de 30 a $35{ }^{\circ} \mathrm{C}$; pré-secagem a temperatura de $50^{\circ} \mathrm{C}$; embebição do substrato do teste de germinação em solução de ácido giberélico e sementes sem tratamento como testemunha. Também foi realizado o teste de tetrazólio, para avaliar a viabilidade das sementes. O delineamento usado foi o inteiramente casualizado e as análises de variância foram efetuadas no esquema fatorial $2 \times 3 \times 5$ (cultivar $\times$ épocas de colheita $\times$ tratamentos para superação de dormência), com quatro repetições por tratamento. Conclui-se que, dentre os tratamentos testados, o mais eficiente foi o uso de temperatura de 5 a $10{ }^{\circ} \mathrm{C}$. A intensidade da dormência e época de colheita das sementes de cevada interfere, diretamente, na eficiência dos tratamentos utilizados para sua superação.
\end{abstract}

Palavras-chave: Hordeum vulgare L; germinação; temperatura; viabilidade; $\mathrm{AG}_{3}$.

\begin{abstract}
The work was done with the objective of studying the efficiency of different treatments to overcome dormancy in barley seeds harvested in different periods. For that, were used seeds of the cultivars MN 721 and Scarlett, evaluated separately. The treatments were as follows: pre-cold temperature from 5 to $10^{\circ} \mathrm{C}$; pre-drying temperature from 30 to $35^{\circ} \mathrm{C}$; pre-drying temperature of $50{ }^{\circ} \mathrm{C}$; soaking of the germination test substratum in giberelic acid solution and seeds without treatment as a check. It was also used the tetrazolium test for evaluating seed viability. The statistical arrangement was in a random design and the analysis of variance was in a factorial $2 \times 3 \times 5$ (two cultivars $\times$ three harvesting periods $\times 5$ treatments for overcoming dormancy), with four replications per treatment. It was concluded that, among the treatments, the most efficient was the temperature of 5 to $10^{\circ} \mathrm{C}$. The intensity of dormancy and the harvesting period of barley seeds interferes, directly, in the efficiency of the treatments used for overcoming dormancy.
\end{abstract}

Key-words: Hordeum vulgare L.; germination; temperature; viability; $\mathrm{GA}_{3}$.

${ }^{1}$ Parte da Dissertação de Mestrado do primeiro autor, apresentado a Universidade Federal de Pelotas (UFPel).

2Engenheira Agrônoma. Estudante do curso de Pós-graduação em Agronomia/Ciência e Tecnologia de Sementes, Departamento de Fitotecnia - Faculdade de Agronomia Eliseu Maciel (FAEM)/ Universidade Federal de Pelotas. Rua Dom Pedro II, n. 629, ap. 102 - Centro. Pelotas, RS, Brasil. CEP: 96010-300. E-mail: lilianmtunes@yahoo.com.br. Autora para correspondência.

${ }^{3}$ Engenheiro Agrônomo. Estudante do Curso de Pós-Graduação em Fisiologia Vegetal - Faculdade de Agronomia Eliseu Maciel/ Universidade Federal de Pelotas. Rosário do Sul, RS, Brasil. E-mail: pgbagro@yahoo.com.br.

${ }^{4}$ Engenheira Agrônoma. Estudante do Curso de Pós-Graduação em Agronomia/Ciência e Tecnologia de Sementes, Depto. Fitotecnia - Faculdade de Agronomia Eliseu Maciel (FAEM)/ Universidade Federal de Pelotas. Vanini, RS, Brasil. E-mail: folivo2@yahoo.com.br.

${ }^{5}$ Engenheiro Agrônomo, Dr., Professor, Departamento de Fitotecnia, Faculdade de Agronomia Eliseu Maciel/Universidade Federal de Pelotas, Caixa Postal: 354, CEP 96001-970, Pelotas, RS, Brasil. E-mail: acbarros@ufpel.edu.br. 


\section{INTRODUÇÃO}

A cevada vem sendo cultivada no Brasil desde a década de 1930. Sua produção está concentrada na Região Sul, com registros de cultivo também nos estados de Goiás, Minas Gerais e São Paulo. Como conseqüência do melhoramento genético e do desenvolvimento de técnicas de manejo cada vez mais apropriadas, a cultura foi difundida pelo sul do Brasil, onde se localizam as melhores áreas, em termos de clima e solo, para o cultivo desse cereal, (Árias, 1995). A área cultivada com essa cultura no país oscila em torno de $100 \mathrm{mil}$ hectares (IBGE, 2007).

A cevada caracteriza-se por ser altamente sensível a precipitações pluviométricas no momento da colheita, principalmente pelo prejuízo causado à germinação das sementes (Reuss et al., 2003). A colheita realizada na fase da maturidade fisiológica (umidade em torno de $30 \%$ ) seria ideal. Nesse momento, a semente atinge o máximo de massa da matéria seca, encontra-se no máximo de sua potencialidade fisiológica e a deterioração é mínima, mas encontra uma série de problemas a serem contornados (Delouche, 2005). Em virtude dessas dificuldades, as sementes permanecem no campo até atingirem nível de umidade adequado para a colheita, sujeitas a condições climáticas nem sempre favoráveis para a preservação de sua qualidade (Barros \& Peske, 2006).

$\mathrm{O}$ fenômeno da dormência é comum. $\mathrm{Na}$ natureza as sementes não germinam logo após a colheita devido a mecanismos internos, de natureza física ou fisiológica, que bloqueiam a germinação. Esses mecanismos são genéticos e ocorrem durante a formação e a maturação da semente, de modo que, logo após a dispersão, a semente ainda não se encontra apta para germinar. Além dos fatores genéticos que influenciam a dormência, as condições ambientais durante o período de desenvolvimento e na maturação das sementes, também exercem esse efeito. Jennings \& Jesus Junior (1964) observaram uma consistente correlação entre baixa germinação e resistência à superação de dormência em sementes de arroz, cuja maturação ocorreu em período chuvoso e com alta umidade relativa do ar. Amaral \& Gonçalo (1977) afirmaram que existe uma variação no grau de dormência conforme o ano de cultivo, e que está associado a outras características próprias da cultivar, que irão propiciar a escolha do método para superá-la em laboratório.

Em cevada, certo grau de dormência é desejável para evitar a germinação ainda na espiga, especialmente em climas com possibilidades de períodos úmidos e chuvas prolongadas durante a colheita, como ocorre no sul do Brasil. A intensidade com que a dormência se expressa está relacionada com o ambiente, especialmente com o comportamento da temperatura e das chuvas, durante períodos críticos na fase de maturação. Para Reiner \& Loch (1976), entre 12 e 16 dias após o espigamento, as baixas temperaturas induzem dormência curta, enquanto temperaturas acima da média induziram dormência mais longa.

Os métodos recomendados para superar a dormência de sementes de cevada que constam nas Regras para Análise de Sementes (BRASIL, 1992) são: pré-secagem à temperatura de 30 a 35 ${ }^{\circ} \mathrm{C}$ por 7 dias; embebição do substrato do teste de germinação em solução de ácido giberélico com concentração de $200 \mathrm{mg} \mathrm{dm}^{-3}$ por 7 dias; e préresfriamento à temperatura de 5 a $10{ }^{\circ} \mathrm{C}$ por 7 dias.

A utilização do teste de tetrazólio tem assumido grande importância no controle de qualidade das sementes de algumas espécies, permitindo a determinação da viabilidade, o que inclui as dormentes. O exame das estruturas do tecido embrionário através da coloração permite obter rápida estimativa do potencial de germinação de sementes dormentes.

O objetivo do presente trabalho foi estudar a eficiência de diferentes tratamentos para superar a dormência em sementes de cevada colhidas em diferentes épocas.

\section{MATERIALE MÉTODOS}

As sementes foram obtidas da empresa Westermann - Comércio e Agropecuária Ltda, localizada no município de Piratini/RS, no ano de 2007 , onde foi realizado o cultivo da cevada e pertencem a classe certificada $\mathrm{C} 1$. As sementes foram trazidas para o Laboratório de Análises de Sementes do Departamento de Fitotecnia, Faculdade de Agronomia Eliseu Maciel, Universidade Federal de Pelotas, para a realização das análises. Foram utilizadas sementes de duas cultivares de cevada, MN 721 e Scarlett, analisadas separadamente. MN 721 originada da AMBEV (Companhia de Bebidas das Américas) apresenta ampla adaptação e responde a ambientes de baixa fertilidade. Scarlett de origem Argentina, possui rendimento elevado e se adapta tanto a clima frio quanto quente. A lavoura que originou o material experimental foi de aproximadamente 0,5 ha. As coletas foram realizadas quando as plantas estavam com 118, 129 e 140 dias após a semeadura e a umidade das sementes foi de $25 \%, 18 \%$ e $13 \%$ respectivamente, para a cultivar $\mathrm{MN} 721$, e para a cultivar Scarlett de $26 \%, 19 \%$ e $13 \%$, respectivamente. Após a colheita as sementes apresentaram, em média, 10 a $12 \%$ de proteínas, dentro dos padrões de qualidade estabelecidos na Portaria 691/96, do Ministério da Agricultura, Pecuária e Abastecimento (BRASIL, 1996). A secagem das sementes foi em estufa com circulação forçada de ar, até atingir $13 \%$ de umidade e então armazenadas em câmara fria, à temperatura de $17^{\circ} \mathrm{C}$ e umidade relativa do ar de $35 \%$, por 18 dias.

Os tratamentos utilizados na superação da dormência das sementes foram os seguintes: préfrio com temperatura de 5 a $10^{\circ} \mathrm{C}$, por 7 dias; présecagem a temperatura de 30 a $35^{\circ} \mathrm{C}$, por 7 dias, em estufa com circulação de ar; pré-secagem a temperatura de $50{ }^{\circ} \mathrm{C}$, em estufa com circulação de 
ar, por 72 h; embebição do substrato do teste de germinação em solução de ácido giberélico com concentração de $200 \mathrm{mg} \mathrm{dm}^{-3}$; e sementes sem tratamento como testemunha.

As avaliações foram realizadas através do teste de germinação (BRASIL, 1992), instalado com quatro repetições de 100 sementes, semeadas em papel toalha umedecidas com água destilada, em quantidade de 2,5 vezes a massa do papel seco. $O$ teste foi conduzido em temperatura de $20{ }^{\circ} \mathrm{C}$ e a contagem realizada no sétimo dia. Avaliou-se o comprimento médio de 10 plântulas normais, escolhidas aleatoriamente, obtidas a partir da semeadura de quatro repetições de 30 sementes; no terço superior da folha de papel toalha, conforme metodologia descrita por Nakagawa (1999). Os rolos de papel contendo as sementes permaneceram por sete dias, em germinador, a temperatura de $20^{\circ} \mathrm{C}$. Determinou-se o comprimento da parte aérea e raiz das plântulas, com auxílio de régua graduada em milímetros. O comprimento médio da parte aérea e da raiz foi obtido somando-se as medidas de cada repetição e dividindo-se pelo número de plântulas normais e os resultados foram expressos em centímetros. Após a medição, as plântulas foram seccionadas, separando-se a parte aérea do sistema radicular. As raízes foram imediatamente colocadas em cápsulas de alumínio e secadas em estufa com circulação de ar, regulada a $65^{\circ} \mathrm{C}$ durante 96 h. Após a secagem foram pesadas para a determinação de massa seca, utilizando-se balança de precisão $(0,0001 \mathrm{mg})$ e os resultados expressos em g por plântula, conforme recomendações de Nakagawa (1994).

O teste de tetrazólio foi realizado para avaliar a viabilidade das sementes. Esse teste foi conduzido com duas repetições de 50 sementes, précondicionadas em substrato umedecido durante 16 $\mathrm{h}$ a temperatura de $25^{\circ} \mathrm{C}$, para facilitar o seccionamento das sementes, de forma longitudinal e medianamente através do embrião. Logo após o corte, as sementes foram imersas em solução a $0,1 \%$ de sal de tetrazólio e levadas para a câmara a $37{ }^{\circ} \mathrm{C}$ durante 2 a $4 \mathrm{~h}$ para a reação. A avaliação foi baseada nos critérios propostos por Grabe (1976).

Foi adotado o delineamento experimental inteiramente casualizado e as análises de variância foram efetuadas no esquema fatorial $2 \times 3 \times 5$ (cultivar $x$ épocas de colheita $x$ tratamentos para superação de dormência), com quatro repetições por tratamento. Utilizou-se a transformação em arcoseno $(x / 100)^{1 / 2}$, para os dados em porcentagens, com o objetivo de normalizar a distribuição. As médias foram comparadas pelo teste de Tukey, utilizando o programa de análises estatísticas SISVAR (Ferreira, 2000). Nas tabelas, as médias foram apresentadas sem transformação.

\section{RESULTADOS E DISCUSSÃO}

$\mathrm{Na}$ Tabela 1, estão apresentados as médias da germinação da testemunha (sem tratamento de superação de dormência), com menor intensidade de dormência inicial na primeira colheita para a cultivar MN 721 e para a cultivar Scarlett na terceira colheita, provavelmente em virtude das condições ambientais reinantes durante o período de maturação das sementes, de acordo com Barros \& Peske (2006). A média da germinação indica que as cultivares MN 721 e Scarlett possuem alto grau de dormência, em todas as épocas de colheita, havendo a necessidade de tratamento específico para a utilização dessas sementes logo depois de colhidas. A cultivar MN 721 apresentou aumento de dormência conforme o avanço no retardamento da colheita. Este comportamento não se repete na cultivar Scarlett, visto que há alta percentagem de sementes que poderiam germinar na espiga, tendendo a aumentar com o retardamento da colheita.

TABELA 1 - Médias do teste de germinação (\%) e resultados dos tratamentos de superação de dormência para cada combinação de época de colheita e cultivares de cevada MN 721 (MN) e Scarlett (SC). Piratini/ RS, safra 2007.

\begin{tabular}{|c|c|c|c|c|c|c|}
\hline Cultivar & $\begin{array}{c}\text { Colheita } \\
\text { (dias) }\end{array}$ & Test. $^{*}$ & $\begin{array}{c}F^{*} \\
\left(5 a 0^{\circ} \mathrm{C}\right)\end{array}$ & $\begin{array}{c}\mathrm{T}^{*} \\
\left(30 \mathrm{a} 35^{\circ} \mathrm{C}\right)\end{array}$ & $\begin{array}{c}\mathrm{T}^{*} \\
\left(50^{\circ} \mathrm{C}\right)\end{array}$ & $\begin{array}{c}\mathrm{AG}_{3}{ }^{*} \\
200 \mathrm{mg} \mathrm{dm}^{-3}\end{array}$ \\
\hline \multirow{3}{*}{ MN 721} & 118 & $59 \mathrm{Ea}$ & $95 \mathrm{Aa}$ & $85 \mathrm{Ca}$ & $81 \mathrm{Db}$ & $92 \mathrm{Ba}$ \\
\hline & 129 & $22 \mathrm{~Eb}$ & $92 \mathrm{Ab}$ & $77 \mathrm{Db}$ & $84 \mathrm{Ca}$ & $89 B b$ \\
\hline & 140 & 9Dc & 96Aa & $82 \mathrm{Ca}$ & $86 \mathrm{Ba}$ & $84 \mathrm{Cc}$ \\
\hline \multicolumn{7}{|l|}{ CV (\%): 2,53} \\
\hline & 118 & $50 \mathrm{Cc}$ & 96Aa & $82 \mathrm{Bb}$ & $80 \mathrm{Bc}$ & $94 \mathrm{Aa}$ \\
\hline Scarlett & $\begin{array}{l}129 \\
140\end{array}$ & $\begin{array}{l}55 \mathrm{Cb} \\
64 \mathrm{Ca}\end{array}$ & $\begin{array}{l}93 A b \\
90 A c\end{array}$ & $\begin{array}{l}\text { 84Bb } \\
89 \mathrm{Aa}\end{array}$ & $\begin{array}{l}92 \mathrm{Aa} \\
89 \mathrm{Ab}\end{array}$ & $\begin{array}{l}91 \mathrm{Ab} \\
86 \mathrm{Bc}\end{array}$ \\
\hline
\end{tabular}

CV (\%): 2,08

${ }^{*}$ Test. (testemunha); $\mathrm{F} 5$ a $10{ }^{\circ} \mathrm{C}$ (frio); $\mathrm{T} 30$ a $35^{\circ} \mathrm{C}$ (temperatura de 30 a $35^{\circ} \mathrm{C}$ ); $\mathrm{T} 50{ }^{\circ} \mathrm{C}$ (temperatura de $50{ }^{\circ} \mathrm{C}$ ) e $\mathrm{AG}_{3} 200 \mathrm{mg}$ $\mathrm{L}^{-1}$ (ácido giberélico). Colheitas (118,129 e 140 dias após a semeadura).

Médias seguidas das mesmas letras, maiúsculas nas linhas e minúsculas nas colunas, não diferem entre si pelo teste de Tukey a $5 \%$ de probabilidade. $\mathrm{CV}=$ coeficiente de variação. 
Quando se optou pelo pré-frio para a superação de dormência em todas as épocas analisadas para a colheita (MN 721 e Scarlett 118, 129 e 140 dias após semeadura), a germinação foi acima de $90 \%$ (Tabela 1 ), sendo elevada para os padrões de sementes, onde o mínimo exigido é de $80 \%$, segundo o Sistema Nacional de Sementes e Mudas - SNSM (2004). Na cultivar MN 721, na coleta dos 118 para 129 dias, houve um decréscimo na germinação de $95 \%$ para $92 \%$, aumentando na época de 140 dias após a semeadura. No entanto a cultivar Scarlett obteve o maior percentual de germinação na primeira coleta (118 dias após a semeadura) e foi diminuindo à medida que se retarda o processo da colheita. Segundo Barros et al. (1999), o teste de frio pode funcionar como um instrumento de grande valor para a seleção prévia de lotes de sementes que apresentam bom potencial de emergência em solos frios e úmidos, condições estas normalmente ocorrentes na região Sul do Brasil.

O tratamento com temperatura de 30 a 35

${ }^{\circ} \mathrm{C}$ em câmara com circulação de ar por um período de sete dias, apresentou diferença estatística (Tabela 1). Na primeira colheita (118 dias após a semeadura) e na terceira colheita (140 dias após a semeadura), cultivar MN 721 e Scarlett respectivamente, foram observados os maiores valores para de germinação. Os resultados obtidos discordam da observação de Ruge (1955), que apenas atribuiu ao aquecimento a aceleração do processo germinativo, e não um aumento na germinação, como ocorreu no presente trabalho, quando se comparou o tratamento com temperatura de 30 a $35^{\circ} \mathrm{C}$ com a testemunha e com diferentes épocas de colheita. A germinação da cultivar MN 721 variou de 77 a $85 \%$ e na cultivar Scarlett de 82 a $89 \%$.

O tratamento com temperatura de $50{ }^{\circ} \mathrm{C}$ foi mais efetivo, na melhoria da germinação em sementes com maior dormência para a cultivar MN 721 , conseguindo o mesmo desempenho em sementes com menor dormência na cultivar Scarlett. Dentro da faixa de temperatura em que as sementes de uma espécie germinam, existe uma temperatura ótima, na qual ocorre o máximo de germinação em menor intervalo de tempo, sendo a mesma variável entre as espécies. Seshu \& Dadlani (1991) afirmaram que o tratamento com calor seco foi mais eficiente na melhoria da germinação em cultivares de arroz com dormência fraca. Observaram que sementes de cultivares com mais dormência necessitam de períodos maiores com tratamento a base de calor para superação da dormência. Esses resultados discordam das informações obtidas por Bevilaqua et al. (1998), onde, as sementes provenientes da primeira colheita apresentaram resultados mais baixos, enquanto aquelas provenientes da segunda colheita apresentaram os resultados mais elevados e as da terceira colheita apresentaram comportamento médio. A germinação da cultivar MN 721 variou de 81 a $86 \%$ e na cultivar Scarlett 80 a $92 \%$.
Tratamento com ácido giberélico $\left(\mathrm{AG}_{3}\right)$, na dosagem de $200 \mathrm{mg} \mathrm{dm}^{-3}$ (Tabela 1 ), estimulou significativamente a superação de dormência nas três épocas de colheita, com germinação acima de $84 \%$ nas duas cultivares. No entanto, para a cultivar MN 721 e Scarlett a maior germinação foi observada na primeira colheita (118 dias após a semeadura) e a mais baixa foi na última coleta (140 dias após a semeadura). Bonow (2008) indicou que a germinação de sementes de arroz pode ser promovida pela mudança hormonal e que o ácido giberélico $\left(\mathrm{AG}_{3}\right)$ atua na promoção da germinação, sendo isto comprovado em espécies de milho e uvaia, de acordo com Aragão et al. (2003); Ferreira et al. (2002) e Scalon et al. (2004). De acordo com Stenzel et al. (2003), sementes de atemóia e frutado-conde que possuem concentração relativa de $\mathrm{AG}_{3}$ baixa, quando tratadas na concentração adequada, teriam germinação mais homogênea e em maior quantidade. Por outro lado, Atencio et al. (2003) observaram que o fator causador de dormência de sementes de acácia é a presença de substâncias inibidoras, que exercem em muitos casos um efeito antagônico ao $\mathrm{AG}_{3}$.

Verificou-se nesse trabalho que o uso de $\mathrm{AG}_{3}$ permitiu obter maiores porcentuais de sementes germinadas que o calor seco. Quando se quer induzir a germinação das sementes logo após a colheita, a aplicação de reguladores vegetais pode ser uma alternativa, o que está de acordo com Aragão et al. (2003), segundo o qual a dormência das sementes pode ser interrompida pela ação de reguladores vegetais. $\mathrm{O}$ comportamento germinativo de cultivares tratados com $\mathrm{AG}_{3}$, pode estar relacionado com o grau de exigência hormonal mais específico para cada cultivar. Em geral, a germinação está mais relacionada com as giberelinas, no entanto algumas espécies têm melhor germinação quando associadas a outros reguladores vegetais. Sua ação no processo germinativo é bem conhecida. Segundo Ferreira et al. (2002) os mesmos atuam no controle da hidrólise do tecido de reserva para o fornecimento de energia ao embrião, promovendo, o alongamento celular, fazendo a radícula se desenvolver através do endosperma ou tegumento. A germinação da cultivar MN 721 variou de 84 a $92 \%$ e na cultivar Scarlett 86 a $94 \%$.

Nas Tabelas 2, 3 e 4 estão apresentadas as médias referentes ao comprimento da parte aérea, comprimento da raiz e massa seca da raiz, respectivamente.

Como as variáveis comprimento da parte aérea e da raiz, sem superação de dormência, os maiores resultados foram encontrados na cultivar MN 721, na terceira colheita (140 dias após a semeadura), quando as sementes apresentavam umidade em torno de 13\%; a massa seca da raiz não apresentou diferença expressiva entre as diferentes colheitas. A cultivar Scarlett não apresentou diferença estatística entre as colheitas para as variáveis comprimento da parte aérea e raiz, no entanto, a massa seca da raiz apresentou-se reduzida na primeira colheita. 
TUNES, L.M. et al. Tratamentos para superação da dormência...

TABELA 2 - Médias do comprimento da parte aérea $(\mathrm{cm})$ e resultados dos tratamentos de superação de dormência para cada combinação de época de colheita e cultivares de cevada MN 721 (MN) e Scarlett (SC). Piratini/RS, safra 2007.

\begin{tabular}{ccccccc}
\hline Cultivar & $\begin{array}{c}\text { Colheita } \\
\text { (dias) }\end{array}$ & Test. & $\begin{array}{c}\mathrm{F}^{*} \\
\left(5 \mathrm{a} 10^{\circ} \mathrm{C}\right)\end{array}$ & $\begin{array}{c}\mathrm{T}^{*} \\
\left(30 \mathrm{a} 35{ }^{\circ} \mathrm{C}\right)\end{array}$ & $\begin{array}{c}\mathrm{T}^{*} \\
\left(50{ }^{\circ} \mathrm{C}\right)\end{array}$ & $\begin{array}{c}\mathrm{AG}_{3}{ }^{*} \\
200 \mathrm{mg} \mathrm{dm}^{-3}\end{array}$ \\
\hline \multirow{3}{*}{ MN 721 } & 118 & $11,80 \mathrm{Cb}$ & $13,06 \mathrm{Ba}$ & $14,59 \mathrm{ABa}$ & $16,38 \mathrm{Aa}$ & $14,94 \mathrm{Aa}$ \\
& 129 & $13,75 \mathrm{Ba}$ & $13,43 \mathrm{Ba}$ & $13,56 \mathrm{Ba}$ & $16,00 \mathrm{Aa}$ & $12,73 \mathrm{Bb}$ \\
& 140 & $13,79 \mathrm{Aa}$ & $12,48 \mathrm{Aab}$ & $11,33 \mathrm{Ab}$ & $11,86 \mathrm{Ab}$ & $10,59 \mathrm{Ac}$ \\
\hline $\mathrm{CV}(\%): 10,26$ & & & & & & $13,24 \mathrm{Aa}$ \\
Scarlett & 118 & $11,13 \mathrm{Ba}$ & $11,41 \mathrm{Bb}$ & $11,50 \mathrm{ABa}$ & $12,41 \mathrm{Aab}$ & $14,00 \mathrm{Aa}$ \\
& 129 & $10,66 \mathrm{Ba}$ & $13,83 \mathrm{Aa}$ & $9,38 \mathrm{Bb}$ & $11,09 \mathrm{Bab}$ & $11,68 \mathrm{Ab}$ \\
\hline $\mathrm{CV}(\%): 11,28$ & 140 & $10,80 \mathrm{ABa}$ & $10,93 \mathrm{ABb}$ & $9,22 \mathrm{Bb}$ & $10,53 \mathrm{ABb}$ &
\end{tabular}

CV (\%): 11,28

${ }^{*}$ Test. (testemunha); $\mathrm{F} 5$ a $10{ }^{\circ} \mathrm{C}$ (frio); $\mathrm{T} 30$ a $35{ }^{\circ} \mathrm{C}$ (temperatura de 30 a $35{ }^{\circ} \mathrm{C}$ ); $\mathrm{T} 50{ }^{\circ} \mathrm{C}$ (temperatura de $50{ }^{\circ} \mathrm{C}$ ) e $\mathrm{AG}_{3} 200$ $\mathrm{mg} \mathrm{L}^{-1}$ (ácido giberélico). Colheitas (118,129 e 140 dias após a semeadura).

Médias seguidas das mesmas letras, maiúsculas nas linhas e minúsculas nas colunas, não diferem entre si pelo teste de Tukey

a $5 \%$ de probabilidade. $\mathrm{CV}=$ coeficiente de variação.

TABELA 3 - Médias do comprimento da raiz $(\mathrm{cm})$ e resultados dos tratamentos de superação de dormência para cada combinação de época de colheita e cultivares de cevada MN 721 (MN) e Scarlett (SC). Piratini/RS, safra 2007.

\begin{tabular}{|c|c|c|c|c|c|c|}
\hline Cultivar & $\begin{array}{c}\text { Colheita } \\
\text { (dias) }\end{array}$ & Test. ${ }^{*}$ & $\begin{array}{c}\mathrm{F}^{*} \\
\left(5 \mathrm{a} 10^{\circ} \mathrm{C}\right)\end{array}$ & $\begin{array}{c}\mathrm{T}^{*} \\
\left(30 \text { a } 35^{\circ} \mathrm{C}\right)\end{array}$ & $\begin{array}{c}\mathrm{T}^{*} \\
\left(50^{\circ} \mathrm{C}\right)\end{array}$ & $\begin{array}{c}\mathrm{AG}_{3}{ }^{*} \\
200 \mathrm{mg} \mathrm{dm}^{-3}\end{array}$ \\
\hline \multirow{3}{*}{ MN 721} & 118 & $6,45 \mathrm{Dc}$ & $23,06 \mathrm{Bb}$ & $16,20 \mathrm{Ca}$ & $24,45 \mathrm{Aa}$ & 24,12Aba \\
\hline & 129 & $7,66 \mathrm{~Eb}$ & $24,15 \mathrm{Aa}$ & $14,07 \mathrm{Db}$ & $19,19 \mathrm{Cb}$ & $23,23 \mathrm{Ba}$ \\
\hline & 140 & 8,83Еa & $25,11 \mathrm{Aa}$ & $13,99 \mathrm{Db}$ & $15,33 \mathrm{Cc}$ & $20,38 \mathrm{Bb}$ \\
\hline \multicolumn{7}{|c|}{ CV (\%): 5,35 } \\
\hline \multirow{3}{*}{ Scarlett } & 118 & $4,01 \mathrm{Da}$ & $21,57 \mathrm{Bb}$ & $13,16 \mathrm{Cb}$ & $26,96 \mathrm{Aa}$ & $21,03 \mathrm{Ba}$ \\
\hline & 129 & $5,03 \mathrm{Da}$ & $24,09 \mathrm{Aa}$ & $18,26 \mathrm{Ca}$ & $23,62 \mathrm{ABb}$ & $22,58 \mathrm{Ba}$ \\
\hline & 140 & $5,53 \mathrm{Da}$ & $24,19 \mathrm{Aa}$ & $17,26 \mathrm{Ca}$ & $24,01 \mathrm{Ab}$ & $21,46 \mathrm{Ba}$ \\
\hline
\end{tabular}

${ }^{*}$ Test. (testemunha); $\mathrm{F} 5$ a $10{ }^{\circ} \mathrm{C}$ (frio); T 30 a $35^{\circ} \mathrm{C}$ (temperatura de 30 a $35^{\circ} \mathrm{C}$ ); $\mathrm{T} 50{ }^{\circ} \mathrm{C}$ (temperatura de $50{ }^{\circ} \mathrm{C}$ ) e $\mathrm{AG}_{3} 200 \mathrm{mg}$ $\mathrm{L}^{-1}$ (ácido giberélico). Colheitas (118,129 e 140 dias após a semeadura).

Médias seguidas das mesmas letras, maiúsculas nas linhas e minúsculas nas colunas, não diferem entre si pelo teste de Tukey a $5 \%$ de probabilidade. $\mathrm{CV}=$ coeficiente de variação.

TABELA 4 - Médias da massa seca da raiz ${ }^{1}(\mathrm{~g})$ e resultados dos tratamentos de superação de dormência para cada combinação de época de colheita e cultivares de cevada MN 721 (MN) e Scarlett (SC). Piratini/RS, safra 2007.

\begin{tabular}{ccccccc}
\hline Cultivar & $\begin{array}{c}\text { Colheita } \\
\text { (dias) }\end{array}$ & Test. & $\begin{array}{c}\mathrm{F}^{*} \\
\left(5 \mathrm{a} 10^{\circ} \mathrm{C}\right)\end{array}$ & $\begin{array}{c}\mathrm{T}^{*} \\
\left(30 \mathrm{a} 35^{\circ} \mathrm{C}\right)\end{array}$ & $\begin{array}{c}\mathrm{T}^{*} \\
\left(50{ }^{\circ} \mathrm{C}\right)\end{array}$ & $\begin{array}{c}\mathrm{AG}_{3}{ }^{*} \\
200 \mathrm{mg} \mathrm{dm}^{-3}\end{array}$ \\
\hline & 118 & $0,013 \mathrm{Aa}$ & $0,035 \mathrm{Ab}$ & $0,029 \mathrm{Aa}$ & $0,029 \mathrm{Aa}$ & $0,031 \mathrm{Aa}$ \\
MN 721 & 129 & $0,018 \mathrm{Ba}$ & $0,076 \mathrm{Aa}$ & $0,039 \mathrm{AB}$ & $0,028 \mathrm{Ba}$ & $0,026 \mathrm{Ba}$ \\
& 140 & $0,033 \mathrm{Aa}$ & $0,036 \mathrm{Ab}$ & $0,039 \mathrm{Aa}$ & $0,034 \mathrm{Aa}$ & $0,024 \mathrm{Aa}$ \\
\hline $\mathrm{CV}(\%): 97,0$ & & & & & & \\
\hline & 118 & $0,009 \mathrm{~Eb}$ & $0,026 \mathrm{Ba}$ & $0,017 \mathrm{Db}$ & $0,042 \mathrm{Ab}$ & $0,022 \mathrm{Ca}$ \\
Scarlett & 129 & $0,011 \mathrm{Ea}$ & $0,026 \mathrm{Ba}$ & $0,017 \mathrm{Db}$ & $0,043 \mathrm{Ab}$ & $0,022 \mathrm{Ca}$ \\
& 140 & $0,010 \mathrm{Dab}$ & $0,026 \mathrm{Ba}$ & $0,026 \mathrm{Ba}$ & $0,044 \mathrm{Aa}$ & $0,016 \mathrm{Cb}$ \\
\hline CV (\%): 5,08 & & &
\end{tabular}

${ }^{1}$ média de dez plântulas.

${ }^{*}$ Test. (testemunha); F 5 a $10{ }^{\circ} \mathrm{C}$ (frio); T 30 a $35^{\circ} \mathrm{C}$ (temperatura de 30 a $35{ }^{\circ} \mathrm{C}$ ); $\mathrm{T} 50{ }^{\circ} \mathrm{C}$ (temperatura de $50{ }^{\circ} \mathrm{C}$ ) e $\mathrm{AG} 3200 \mathrm{mg}$ $\mathrm{L}^{-1}$ (ácido giberélico). Colheitas (118,129 e 140 dias após a semeadura).

Médias seguidas das mesmas letras, maiúsculas nas linhas e minúsculas nas colunas, não diferem entre si pelo teste de Tukey a $5 \%$ de probabilidade. $\mathrm{CV}=$ coeficiente de variação.

Quando o tratamento de frio foi aplicado para ambas cultivares, o comprimento da parte aérea foi maior na segunda colheita (129 dias após a semeadura). Para a variável comprimento da raiz, este teste apresentou maiores resultados na terceira colheita. Para a massa seca da raiz, na cultivar MN 721 , maiores valores foram observados na segunda colheita (129 dias após a semeadura), no entanto, a cultivar Scarlett não apresentou diferença na massa seca entre as colheitas.

O comprimento da parte aérea com superação de dormência usando o frio não apresentou diferença quando comparado com a testemunha (sem superação de dormência), no entanto, mas o comprimento da raiz variou expressivamente nas duas cultivares. 
TUNES, L.M. et al. Tratamentos para superação da dormência...

Temperatura de 35 e $50{ }^{\circ} \mathrm{C}$, tiveram maior resultado na primeira colheita na cultivar MN 721 para todas variáveis com exceção da massa seca da raiz, no entanto, na cultivar Scarlett, a primeira colheita foi a mais expressiva para o comprimento da parte aérea e para o comprimento da raiz. A massa seca da raiz para ambas cultivares foi maior na última colheita, ou seja, 140 dias após a semeadura. Para o tratamento com temperatura de $50{ }^{\circ} \mathrm{C}$ a cultivar Scarlett obteve valores expressivos em relação a cultivar $M N$ 721. O crescimento e desenvolvimento de plântulas parecem ser os mesmos para ambas cultivares. O sistema radicular tende a se desenvolver mais rapidamente que a parte aérea, visto que possui praticamente o dobro do comprimento.

O comportamento do tratamento com $\mathrm{AG}_{3}$ foi similar ao do frio. De acordo com Bonow (2008), na dormência fisiológica, o embrião, apesar de fisicamente estruturado, completo, não se desenvolve por razões tais como balanço hormonal inadequado, impermeabilidade a trocas gasosas (oxigênio e, ou gás carbônico) ou presença de compostos químicos inibidores. A superação dessa dormência envolve modificações hormonais no embrião, ou seja, tanto a redução da concentração dos inibidores como a síntese de fitohormônios promotores da germinação. Dessa maneira, o contato direto das sementes em solução de $\mathrm{AG}_{3}$ é eficaz para algumas espécies, como a cevada. Dentre os tratamentos empregados, dois métodos se mostraram eficientes em superar a dormência de sementes de cevada, independente da época de colheita, o uso de temperatura de 5 a $10{ }^{\circ} \mathrm{C}$ e $A_{3}$.

O teste de tetrazólio foi utilizado para determinar o percentual de sementes vivas (Tabela $5)$, verificando-se a alta viabilidade das sementes. À medida que diminui o percentual de umidade das sementes (retardamento da colheita), observou-se pequena diminuição da viabilidade de ambas as cultivares. Segundo Halmer \& Bewley (1984), a maior parte das mudanças no metabolismo básico da semente está associada a reduções de viabilidade, as quais afetam diretamente o desenvolvimento das sementes. Esse comportamento se deve, provavelmente ao consumo de reservas nutritivas na fase de pré-colheita. Neste caso, deve-se determinar previamente se o produto desejado é semente ou grão para a produção de malte e assim, determinar o ponto de colheita ideal para cada cultivar, para evitar perdas na produção. Obtiveramse mais sementes viáveis na cultivar MN 721 e Scarlett na primeira e segunda colheita (118 e 129 dias após a semeadura).

TABELA 5 - Médias do teste de tetrazólio (\%) e resultados dos tratamentos de superação de dormência para cada combinação de época de colheita e cultivares de cevada MN 721 (MN) e Scarlett (SC). Piratini/RS, safra 2007.

\begin{tabular}{|c|c|c|c|c|c|c|}
\hline Cultivar & $\begin{array}{c}\text { Colheita } \\
\text { (dias) }\end{array}$ & Test. ${ }^{*}$ & $\begin{array}{c}\mathrm{F}^{*} \\
\left(5 \text { a } 10^{\circ} \mathrm{C}\right)\end{array}$ & $\begin{array}{c}\mathrm{T}^{*} \\
\left(30 \text { a } 35^{\circ} \mathrm{C}\right)\end{array}$ & $\begin{array}{c}\mathrm{T}^{*} \\
\left(50^{\circ} \mathrm{C}\right)\end{array}$ & $\begin{array}{c}\mathrm{AG}_{3}{ }^{*} \\
\left(200 \mathrm{mg} \mathrm{dm}^{-3}\right)\end{array}$ \\
\hline \multirow{3}{*}{ MN 721} & 118 & 99Aa & $98 \mathrm{Aa}$ & 98Aa & $98 \mathrm{Aa}$ & 97Aa \\
\hline & 129 & $97 \mathrm{Aa}$ & $96 \mathrm{Ab}$ & $96 \mathrm{Ab}$ & $96 \mathrm{Ab}$ & $95 \mathrm{Bb}$ \\
\hline & 140 & $96 \mathrm{Ab}$ & $95 A c$ & $95 A c$ & $94 \mathrm{Bc}$ & $94 \mathrm{Bc}$ \\
\hline \multicolumn{7}{|c|}{ CV (\%): 1,09 } \\
\hline \multirow{3}{*}{ Scarlett } & 118 & 98Aa & $97 \mathrm{Aa}$ & $98 \mathrm{Aa}$ & $95 \mathrm{Ba}$ & $92 \mathrm{Ba}$ \\
\hline & 129 & $98 \mathrm{Aa}$ & 97Aa & $97 \mathrm{Ab}$ & $95 \mathrm{Ba}$ & $91 \mathrm{Cb}$ \\
\hline & 140 & $98 \mathrm{Aa}$ & 97Aa & $97 \mathrm{Ab}$ & $95 \mathrm{Ba}$ & $90 \mathrm{Cc}$ \\
\hline
\end{tabular}

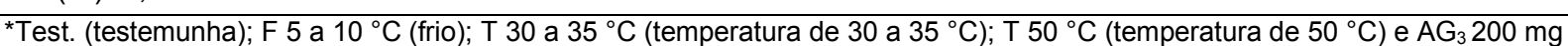
$\mathrm{L}^{-1}$ (ácido giberélico). Colheitas (118,129 e 140 dias após a semeadura).

Médias seguidas das mesmas letras, maiúsculas nas linhas e minúsculas nas colunas, não diferem entre si pelo teste de Tukey a $5 \%$ de probabilidade. CV = coeficiente de variação.

Conhecer os mecanismos de dormência e a sua duração para as diferentes espécies tem importância econômica, pois auxilia na definição sobre a necessidade ou não de se utilizar tratamentos especiais para liberar o embrião para o desenvolvimento ou tornando-o apto para o crescimento.

Verifica-se, assim, que a época de colheita das sementes pode afetar o poder germinativo, além de apresentar resultados diferenciados após o tratamento de superação de dormência (Tabela 1).

As sementes da cultivar MN 721, na terceira colheita (140 dias após a semeadura) apresentaram maior percentual de germinação com o uso de praticamente todos os tratamentos, com exceção apenas do $\mathrm{AG}_{3}$, que obteve maiores valores quando as sementes estavam próximas a $30 \%$ de umidade, ou seja, na primeira colheita (118 dias após a semeadura). Os tratamentos foram mais eficientes para essa cultivar na primeira e terceira colheita, quando as sementes foram colhidas com umidade em torno de 26 e $13 \%$ de umidade, respectivamente. Para a cultivar Scarlett, que é de ciclo mais longo, o melhor tratamento para superar a dormência em diferentes épocas de colheita, foi a temperatura de 5 a $10{ }^{\circ} \mathrm{C}$, seguido do $\mathrm{AG}_{3} ; 50{ }^{\circ} \mathrm{C}$ e de 30 a $35{ }^{\circ} \mathrm{C}$, em ordem decrescente. 
TUNES, L.M. et al. Tratamentos para superação da dormência...

\section{CONCLUSÕES}

1) As sementes de cevada logo depois de colhidas apresentam alta dormência.

2) A dormência teve comportamento diferente, dependendo da cultivar e da época de colheita.

3) Dentre os tratamentos testados, o mais eficiente foi o uso de temperatura de 5 a $10{ }^{\circ} \mathrm{C}$ por sete dias.

\section{AGRADECIMENTOS}

À Empresa Westermann, do Município de Piratini, RS, pelo fornecimento da área para a pesquisa; ao Laboratório Didático de Análise de Sementes Prof. Flávio Rocha, do Departamento de Fitotecnia, Faculdade de Agronomia Eliseu Maciel, da Universidade Federal de Pelotas; a Capes, pelo apoio e financiamento do projeto de pesquisa.

\section{REFERÊNCIAS}

1. AMARAL, A. S.; GONÇALO, J. F. P. Dormência em sementes de arroz. Lavoura Arrozeira, v. 30, n. 301, p. 35-7, 1977.

2. ARAGÃO, C. A. et al. Atividade amilolítica e qualidade fisiológica de sementes armazenadas de milho super doce tratadas com ácido giberélico. Revista Brasileira de Sementes, v. 25, n. 1, p. 43-48, 2003.

3. ÁRIAS, G. Mejoramiento genético y producción de cebada cervecera en América del Sur. Santiago: FAO, 1995. $157 \mathrm{p}$.

4. ATENCIO, L. et al. Tratamientos pregerminativos en acacia San Francisco (Peltophorum pterocarpum) Fabaceae. Revista da Faculdade de Agronomia, v. 20, n. 1, p. 63-71, 2003.

5. BARROS, A. S. et al. Testes de frio. In: KRZYZANOWSKI, F. C. et al. Vigor de sementes: conceitos e testes. Londrina: ABRATES, 1999. cap. 5, p. 1-15.

6. BARROS, A. C. S. A.; PESKE, S. T. Produção de Sementes. In: PESKE, S. T.; LUCCA, O. F.; BARROS, A. C. S. A. Sementes: Fundamentos científicos e tecnológicos. 2. ed. Pelotas: UFPEL, 2006. v. 2. p. 470-498.

7. BEVILAQUA, G. A. P. et al. Efeito do tratamento de sementes de cenoura com reguladores de crescimento. Pesquisa Agropecuária Brasileira, v. 33, n. 8, p. 1271-1280, 1998.

8. BONOW, N. R. Dormência e Germinação de Sementes de Arroz. Seed News, v. 7, n. 1, p. 42, 2008.

9. BRASIL. Ministério da Agricultura e da Reforma Agrária. Regras para análise de sementes. Brasília: SNDA/DNDV/ CLAV, 1992. $365 \mathrm{p}$

10. BRASIL. Ministério da Agricultura, Pecuária e Abastecimento. Portaria ${ }^{\circ} 691$ de 22 de novembro de 1996. Diário Oficial da União, Seção 1, p. 24751-24752, 25 nov. 1996.

11. DELOUCHE, J. C. Qualidade e desempenho da semente. Seed News, v. 4, n. 5, p. 34-35, 2005

12. FERREIRA, D. F. Análises estatísticas por meio do SISVAR para windows versão 4.0. In: REUNIÃO ANUAL DA REGIÃO BRASILEIRA DA SOCIEDADE INTERNACIONAL DE BIOMETRIA, 45., São Carlos. Anais. São Carlos: UFSCAR, 2000. p. 225-258

13. FERREIRA, G.; ERIG, P. R.; MORO, E. Uso de ácido giberélico em sementes de fruta-do-conde (Annona squamosa L) visando à produção de mudas em diferentes embalagens. Revista Brasileira de Fruticultura, v. 24, n. 1, p. 178-182, 2002.

14. GRABE, D. F. Manual do teste de tetrazólio em sementes. Brasília: Agiplan, 1976. 85 p.

15. HALMER, P.; BEWLEY, J. D. A physiological perspective on seed vigour testing. Seed Science and Technology, v. 12, n. 2, p. 561-575, 1984.

16. INSTITUTO BRASILEIRO DE GEOGRAFIA E ESTATÍSTICA (IBGE). Levantamento sistemático de produção agrícola. Disponível em: <http://www.ibge.gov.br/indicadores/agropecuaria/ispa>. Acesso em: 11 maio 2007.

17. JENNINGS, P. R.; JESUS JÚNIOR, J. Effect of heat on breaking seed dormancy in rice. Crop Science, v. 4, n. 5, p. 530533, 1964

18. NAKAGAWA, J. Testes de vigor baseados na avaliação das plântulas. In: VIEIRA, R. D.; CARVALHO, N. M. Testes de vigor em sementes. Jaboticabal: FUNEP, 1994. p. 49-85.

19. NAKAGAWA, J. Testes de vigor baseados no desempenho de plântulas. In: KRZYZANOWSKI, F. C.; VIEIRA, R. D.; FRANÇANETO, J. B. Vigor de sementes: conceitos e testes. 2. ed. Londrina: ABRATES, 1999. v. 2, p. 1-21.

20. REINER, L.; LOCH, N. Ein vorhersageverfahren bei braugerste. Brauwissenschaft, v. 29, n. 2, p. 167-168, 1976.

21. REUSS, R.; CASSELLS, J. A.; GREEN, J. R. Malting barley: storage, dormancy and processing quality. In: AUSTRALIAN POSTHARVEST TECHNICAL CONFERENCE, 2003, Camberra. Proceedings. Camberra: Stored Grain Research Laboratory, 2003. p. 44-48.

22. RUGE, E. The analysis of seed heating in Malvaceae. Chemical Abstracts, v. 49, n. 3, p. 117-185, 1955.

23. SCALON, S. P. Q.; SCALON FILHO, H.; RIGONI, M. R. Armazenamento e germinação de sementes de uvaia Eugenia uvalha Cambess. Ciência e Agrotecnologia, v. 28, n. 6, p. 1228-1234, 2004.

24. SESHU, D. V.; DADLANI, M. Mechanism of seed dormancy in rice. Seed Science Research, v. 1, n. 3, p. 187-94, 1991.

25. SISTEMA NACIONAL DE SEMENTES E MUDAS (SNSM). Portaria $n^{\circ} 528$ de 25 de março de 2004. Diário Oficial da União, Seção 1, p. 6, 23 jul. 2004

26. STENZEL, N. M. C.; MURATA, I. M.; NEVES, C. S. V. J. Superação de dormência em sementes de atemóia e fruta-do-conde. Revista Brasileira de Fruticultura, v. 25, n. 2, p. 305-308, 2003. 
